\title{
Association of predicted 10 years cardiovascular mortality risk with duration of HIV infection and antiretroviral therapy among HIV-infected individuals in Durban, South Africa
}

Olamide O. Todowede ${ }^{1 *}$, Benn Sartorius ${ }^{1,2,4}$, Nombulelo Magula ${ }^{3}$ and Aletta E. Schutte ${ }^{5,6}$

\begin{abstract}
Background: South Africa has the largest population of human immunodeficiency virus (HIV) infected patients on antiretroviral therapy (ART) realising the benefits of increased life expectancy. However, this population may be susceptible to cardiovascular disease (CVD) development, due to the chronic consequences of a lifestyle-related combination of risk factors, HIV infection and ART. We predicted a 10-year cardiovascular mortality risk in an HIV-infected population on long-term ART, based on their observed metabolic risk factor profile.

Methods: We extracted data from hospital medical charts for 384 randomly selected HIV-infected patients aged $\geq 30$ years. We defined metabolic syndrome (MetS) subcomponents using the International Diabetes Federation definition. A validated non-laboratory-based model for predicting a 10-year CVD mortality risk was applied and categorised into five levels, with the thresholds ranging from very low-risk $(<5 \%)$ to very high-risk scores $(>30 \%)$.

Results: Among the 384 patients, with a mean ( \pm standard deviation) age of $42.90 \pm 8.20$ years, the proportion of patients that were overweight/obese was 53.3\%, where 50.9\% had low high-density lipoprotein (HDL) cholesterol and $21(17.5 \%)$ had metabolic syndrome. A total of 144 patients with complete data allowed a definitive prediction of a 10-year CVD mortality risk. 52\% (95\% Cl 44-60) of the patients were stratified to very low risk $(<5 \%)$ compared to $8 \%(95 \% \mathrm{Cl} 4-13)$ that were at a very high risk (> 30\%) of 10-year CVD mortality. The CVD risk grows with increasing age (years), $57.82 \pm 6.27$ among very high risk and 37.52 $\pm 4.50 ; p<0.001$ in very low risk patients. Adjusting for age and analysing CVD risk mortality as a continuous risk score, increasing duration of HIV infection $(p=0.002)$ and ART $(p=0.007)$ were significantly associated with increased predicted 10 year CVD mortality risk. However, there was no association between these factors and categorised CVD mortality risk as per recommended scoring thresholds.
\end{abstract}

Conclusions: Approximately 1 in $10 \mathrm{HIV}$-infected patients is at very high risk of predicted 10-year CVD mortality in our study population. Like uninfected individuals, our study found increased age as a major predictor of 10-year mortality risk and high prevalence of metabolic syndrome. Additional CVD mortality risk due to the duration of HIV infection and ART was seen in our population, further studies in larger and more representative study samples are

\footnotetext{
*Correspondence: lamide.ayodele@gmail.com

${ }^{1}$ Public Health Medicine, School of Nursing and Public Health, University

of KwaZulu-Natal, Durban 4001, South Africa

Full list of author information is available at the end of the article
}

(c) The Author(s) 2019. This article is licensed under a Creative Commons Attribution 4.0 International License, which permits use, sharing, adaptation, distribution and reproduction in any medium or format, as long as you give appropriate credit to the original author(s) and the source, provide a link to the Creative Commons licence, and indicate if changes were made. The images or other third party material in this article are included in the article's Creative Commons licence, unless indicated otherwise in a credit line to the material. If material is not included in the article's Creative Commons licence and your intended use is not permitted by statutory regulation or exceeds the permitted use, you will need to obtain permission directly from the copyright holder. To view a copy of this licence, visit http://creativeco mmons.org/licenses/by/4.0/. The Creative Commons Public Domain Dedication waiver (http://creativecommons.org/publicdomain/ zero/1.0/) applies to the data made available in this article, unless otherwise stated in a credit line to the data. 
encouraged. It recommends an urgent need for early planning, prevention and management of metabolic risk factors in HIV populations, at the point of ART initiation.

Keywords: HIV, Cardiovascular risk score, Metabolic syndrome, Antiretroviral therapy

\section{Background}

The introduction of antiretroviral therapy (ART) in the management of human immunodeficiency virus (HIV) infection has resulted in increased life expectancy of infected patients, altering HIV pathogenesis from an acute to a chronic disease [1]. Despite this recognizable success of ART, there are still challenges faced by people living with HIV, such as increased prevalence of metabolic and cardiovascular abnormalities such as lipid abnormalities, diabetes and hypertension [2, 3]. These conditions can occur individually, but more often occur as a cluster of cardiovascular disease (CVD) risk factors, known as metabolic syndrome (MetS), which increases the risk of CVD above what is anticipated for any individual risk factor [4-8].

HIV-infected individuals have a twofold higher risk of CVD morbidity and mortality compared to their uninfected counterparts [9-11]. The main factors leading to these events include HIV infection, inflammation and autoimmune response, ART and the high cardiovascular risk profile of HIV-infected patients [12-14]. The mechanisms of these factors to induce cardiovascular risk are not clear, although an interplay between factors and their complexities have been suggested [15]. CVD risk varies by demographic and clinical factors of the HIV infected populations, for instance some studies showed that severe co-infection increased the risk of CVD in their population while ART adherence and high CD4 count reduce the risk $[16,17]$. Other studies indicated the role of protease inhibitors and abacavir, HIV associated inflammation and immune activation to accentuate the risk of CVD among HIV infected populations [18, 19]. Moreover, lifestyle-related CVD risk factors such as diet, obesity, alcohol intake and smoking, common among the general population, further compound the susceptibility of people living with HIV to increased metabolic disturbance $[14,20]$. Corroborating evidence indicates increased CVD mortality among people with individual and clustered risk factors (MetS), especially in men and older populations [21, 22].

A systematic review and meta-analysis conducted among HIV-infected populations in sub-Saharan African (SSA) countries indicated a strong association between the use of ART and CVD mortality risk [23]. Similarly, another meta-analysis suggested HIV infection is a consistent risk factor for CVD outcomes, though this varied by geographical location [12]. The association of ART and HIV infection with increased CVD risk has been mostly documented in high-income countries (HIC). However, there is paucity of data reporting this in HIVhyperendemic setting and in many low-and-middleincome countries (LMICs) [24]. A study in Uganda estimated the 10-year absolute risk of cardiovascular diseases (CVD) among HIV infected populations who were on ART [25]. The association between HIV and CVD risk could be modified in LMIC settings due to other contributors occurring in many of them, such as rapid nutritional, early onset of HIV infection and ART uptake and epidemiological transitions.

Therefore, understanding the potential CVD burden in a hyperendemic HIV context is important to inform routine clinical care, as well as for its prevention and management by clinicians [26, 27]. We therefore assessed the burden of metabolic risk factors and predicted 10-year CVD mortality risk in an HIV-infected population on long-term ART. We further evaluated the relationship between duration of HIV infection and ART use and the predicted 10-year CVD mortality.

\section{Methods \\ Aim of the study}

The aim was to assess the burden of metabolic risk factors and predict 10-year CVD mortality risk in an HIVinfected population on long-term ART. We showed the relationship between the duration of HIV infection and ART on cardiovascular mortality risk.

\section{Study sample}

This study is a cross-sectional study (medical chart review) of HIV-infected patients attending Addington Hospital's antiretroviral clinic an urban setting in Durban, South Africa, from 2004 to 2017. We extracted data from 384 patient files, selected using a simple random sampling approach from a total population of $\sim 3800$ unique patient files available over this period. A patient was deemed eligible if they attended at least one follow-up visit after ART initiation and was aged $\geq 30$ years. These criteria are supported by the South African guidelines for the management of HIV/AIDS, which indicate that HIV-infected patients should have at least two followup visits per year [28]. A non-laboratory-based approach was employed for estimating 10-year CVD mortality risk among our HIV-infected cohort, this was implored as a result of missing total cholesterol measurement from 
most patients charts at the facility. Evidence suggests that the use of body mass index (BMI) instead of total cholesterol levels gives a similar or better prediction of CVD risk estimation, especially in low resource settings with limited access to laboratory testing $[29,30]$. The model incorporates the following risk factors in the prediction: age, BMI, current smoker, history and or presence of diabetes, history of blood pressure treatment and systolic blood pressure [30]. The predicted CVD mortality risk was analyzed as a continuous and categorical variable, and the categorized variant was based on the following conventional thresholds: 'very low' $(<5 \%)$, 'low' (5-9.9\%), 'moderate' (10-19.9\%), 'high' (20-29.9\%), and 'very high' (> 30\%) [31, 32]. Ethical approval for this study was obtained from the Biomedical Research Ethics Committee (BREC), reference number (BE437/16), at the University of KwaZulu-Natal.

\section{Data collection}

Data were extracted from patient charts using a standardized instrument that was pilot tested. The following information was extracted: demographic-age, sex, race, place of residence; risk factors-smoking, adherence to ART treatment, past and present tuberculosis diagnosis, blood pressure readings; and anthropometric-baseline BMI, height and weight. We also extracted blood profile results for fasting plasma glucose and lipid laboratory data (serum HDL cholesterol level, total cholesterol, serum LDL cholesterol, triglycerides); dates of HIVinfection confirmation and ART initiation; and records of present treatment of hypertension and type 2 diabetes. Other comorbidities (known and recorded presence of non-communicable diseases in the patient's chart) were extracted when available. If available, data were tracked for all patients at baseline and for at least one or more subsequent follow-up visit at the time of this chart audit. Information on the current and past ART regimen per patient was also extracted. Data captured on the same date as ART initiation are classified as the patient's baseline record in this study and ordered sequentially for subsequent visits based on the date of presentation. Data were double-entered into an Epi Info 7 database with built-in validation checks.

\section{Metabolic risk factor classification}

We used the cutoff for raised fasting plasma glucose of $\geq 100 \mathrm{mg} / \mathrm{dL}$ or $5.6 \mathrm{mmol} / \mathrm{L}$ or reported diagnosis and treatment for type 2 diabetes. Similarly, high blood pressure was referred to as systolic pressure of $\geq 130 \mathrm{mmHg}$ and/or a diastolic pressure of $\geq 85 \mathrm{mmHg}$ or reported diagnosis and treatment for hypertension. Other risk factors were defined as raised triglycerides $>150 \mathrm{mg} /$ $\mathrm{dL}(1.7 \mathrm{mmol} / \mathrm{L})$, reduced HDL cholesterol $(<40 \mathrm{mg} / \mathrm{dL}$
$(1.03 \mathrm{mmol} / \mathrm{L})$ in men and $<50 \mathrm{mg} / \mathrm{dL}(1.29 \mathrm{mmol} / \mathrm{L})$ in women) or specific treatment for this lipid abnormality. These definitions are incorporated using the International Diabetes Federation (IDF) definitions for MetS [33]. Body mass index (BMI) was classified into the following three categories: normal $<25 \mathrm{~kg} / \mathrm{m}^{2}$, overweight $25-29.9 \mathrm{~kg} / \mathrm{m}^{2}$, and obese $\geq 30 \mathrm{~kg} / \mathrm{m}^{2}$.

\section{Data analysis}

Data were analysed using STATA version 13.0 [34]. The mean and standard deviation (SD) or median (25th75th percentiles) were calculated for continuous variables. Difference between means was assessed using the Student's $t$-test or Wilcoxon rank-sum test (also known as the Mann-Whitney $U$ test), if the normality assumption was not upheld. The Pearson Chi square $\left(x^{2}\right)$ test was used to measure the strength of linear relationship or the Fisher's exact test (if fewer than 5 expected observations in all cells in the contingency table) was used to test the association between categorical variables. The correlation between the predicted CVD risks was assessed using the Spearman correlation; whereas the differences in the correlation coefficients across the various settings were tested using the Steiger's Z test. All statistical tests were assessed at a $5 \%$ significance level.

\section{Results}

\section{Characteristics of the study participants}

A total of 384 randomly selected patient charts were included in this study, with the socio-demographic description of individual risk factors presented in Table 1. However, only 144 patients had complete chart records on all the risk factors required for the assessment of their CVD mortality risk (Fig. 1). Of the 384 patient charts, we observed a mean age of 42.9 (SD8.2) years, 256 (66.3\%) were female, and 353 (91.7\%) were Black African. The age distribution of the patients are 30-34 (16.15\%), 35-39 (27.08\%), 40-44 (21.88\%), 45-49 (14.58\%), 50-59 (4.17\%), 60-64 (3.13\%) and $1.30 \%$ were aged 65 years and above. The mean duration of participants confirmed to be HIV infected was $6.3 \pm 4$ years. Overall, 201 (52.1\%) and 107 (27.7\%) participants had, or were presently taking, the first- and second-line ART, respectively, with only two patients on third-line therapy. However, 76 (19.7\%) had a missing record of the past or present class of regimen. Tuberculosis infection was the highest comorbidity, with $157(45 \%)$ patients having been previously infected. The most common noncommunicable disease (NCD) comorbidities among participants were 30 (7.5\%) with hypertension, $22(5.7 \%)$ with renal impairment, 14 (3.6\%) with asthma and there were no cases of lipodystrophy. Overall, 270 patients had a useable baseline BMI measurement, with a mean BMI of $26.5 \pm 6.8 \mathrm{~kg} / \mathrm{m}^{2}$. Women [54 
Table 1 Characteristics of the study participants $(\mathbf{N}=384)$

\begin{tabular}{|c|c|c|c|c|c|}
\hline Characteristics & $\mathbf{N}$ & $\begin{array}{l}\text { All patients } \\
(\text { mean } \pm S D)\end{array}$ & Men (mean \pm SD) & Women (mean \pm SD) & P-value ${ }^{i}$ \\
\hline Age (years) & 384 & $42.82(8.3)$ & $43.26(8.2)$ & $42.54(8.4)$ & 0.121 \\
\hline HIV infection duration (years) & 220 & $6.33(3.9)$ & $5.78(4.0)$ & $6.72(3.9)$ & $0.047^{*}$ \\
\hline ART duration (years) & 383 & $6.18(3.43)$ & $5.82(3.5)$ & $6.39(3.4)$ & $0.094^{\#}$ \\
\hline 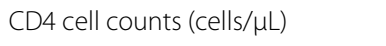 & 364 & $407.5(254.6)$ & $347.9(207.2)$ & $437.9(271.0)$ & $0.005^{* *}$ \\
\hline Height (metres) & 270 & $162.7(9.2)$ & $169.1(9.6)$ & $159.5(7.2)$ & $<0.001^{* *}$ \\
\hline Weight (Kg) & 377 & $70.8(17.0)$ & $69.1(14.0)$ & $71.7(18.3)$ & 0.324 \\
\hline $\mathrm{BMI}\left(\mathrm{kg} / \mathrm{m}^{2}\right)$ & 270 & $26.5(6.8)$ & $23.7(5.7)$ & $27.9(6.8)$ & $<0.001^{* *}$ \\
\hline Systolic blood pressure (mmHg) & 206 & $120.3(19.8)$ & $129.7(25.7)$ & $118.2(17.3)$ & $0.052^{\#}$ \\
\hline Diastolic blood pressure (mmHg) & 207 & $80.6(55.0)$ & $79.8(18.1)$ & $80.9(63.5)$ & 0.191 \\
\hline Blood glucose (mmol/L) & 246 & $5.6(2.4)$ & $5.8(2.4)$ & $5.5(2.5)$ & $0.012^{*}$ \\
\hline Triglycerides (mmol/L) & 111 & $1.6(1.1)$ & $1.9(1.4)$ & $1.5(0.9)$ & $0.096^{\#}$ \\
\hline HDL cholesterol (mmol/L) & 112 & $1.3(0.4)$ & $1.2(0.3)$ & $1.3(0.4)$ & 0.194 \\
\hline
\end{tabular}

: Wilcoxon rank-sum test; ${ }^{* *}$ : significant at $1 \%$ level; ${ }^{*}$ : significant at $5 \%$ level; ${ }^{\#}$ : significant at $10 \%$ level

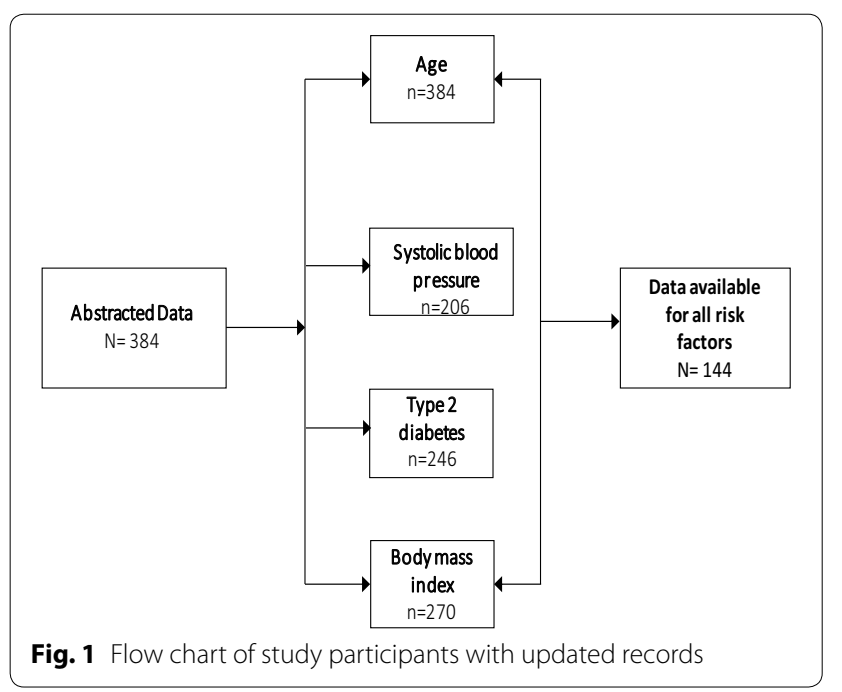

(29.7\%)] were significantly more overweight than men [9 $(8 \%) ; \mathrm{p}<0.001]$ and $61(33.5 \%)$ women versus $21(23.6 \%)$ men $[\mathrm{p}<0.001]$ were obese.

\section{Prevalence of metabolic syndrome and metabolic risk factors}

The prevalence of individual metabolic risk factors of the study participants at baseline (i.e. treatment initiation) is shown in Table 2. Of the 270 patients with a valid BMI classification, 144 (53.2\%) were overweight or obese. Among the 206 patients with a blood pressure measurement taken at baseline, most were classified in the normal blood pressure range, at 163 (79.1\%). Similarly, among the 246 patients with blood glucose records and the 111 patients with triglyceride records,
$74 \%$ were classified in the normal blood glucose range and $66.7 \%$ had normal triglyceride levels respectively. An almost equal proportion of the patients with HDL cholesterol records presented with both low HDL cholesterol and a normal range of the good cholesterol [57 (50.9\%) vs 55 (49.1\%); $\mathrm{p}<0.010]$. Among the 384 participants, there were 165 that could be reliably classified using the IDF MetS definitions alluded to previously, due to missing subcomponent data. Among these 165 participants, $21(17.5 \%)$ were classified as having MetS, with higher prevalence in females [19 (90.5\%)] than males [2 (9.5\%)]. There was no statistically significant difference in the age distribution when stratified by metabolic syndrome classification ( $\mathrm{p}=0.102)$, (Additional file 1: Table S3).

\section{Estimated 10-year cardiovascular mortality risk}

A total of 144 patients had a complete dataset that was modeled for predicting 10-year cardiovascular mortality risk; of these, 107 were females. In this study, the largest proportion of the population belonged in the very low risk group $(<5 \%)$ at $52.1 \%$ [ $(75 / 144,0.52(95 \%$ CI $0.44-$ $0.60)$ ]. This was $57.0 \%$ among females and $37.8 \%$ among males $(p=0.136)$. A significant decrease in the proportion of patients is observed as the prediction moves from very low risk $(<5 \%)$ to very high risk $(>30 \%)-$ Fig. 2. Approximately $6 \%[(9 / 144,0.06$ (95\% CI $0.03-0.12)]$ of this study population were classified in the low risk (20-29.9\%) 10-year CVD mortality risk category. Similarly, about $8 \%$ [(0.08 (95\% CI $0.04-0.13)]$ of the patients were at a greater than $30 \% 10$-year risk of CVD mortality. However, the stratification of the proportion of our study sample, by the CVD mortality risk scores, was statistically insignificant (Fig. $2 \mathrm{p}=0.136$ ). There was a significant positive association between presence of Mets and 
Table 2 Prevalence of individual risk factors for cardiovascular disease

\begin{tabular}{|c|c|c|c|c|c|}
\hline Characteristic & Range & $\begin{array}{l}\text { Overall } \\
(384) \\
n(\%)\end{array}$ & $\begin{array}{l}\text { Male (128) } \\
\mathrm{n}(\%)\end{array}$ & $\begin{array}{l}\text { Female (256) } \\
\text { n (\%) }\end{array}$ & p-value \\
\hline \multirow[t]{4}{*}{$\mathrm{BMI}\left(\mathrm{Kg} / \mathrm{m}^{2}\right)$} & Underweight & $12(4.4)$ & $7(7.9)$ & $5(2.7)$ & $<0.001$ \\
\hline & Normal & $115(42.4)$ & $53(59.6)$ & $62(34.1)$ & \\
\hline & Overweight & $75(27.7)$ & $21(23.6)$ & $54(29.7)$ & \\
\hline & Obese & $69(25.5)$ & $8(9)$ & $61(33.5)$ & \\
\hline \multirow[t]{2}{*}{ Blood pressure (mmHg) } & $<130 / 80$ & $163(79.1)$ & $42(75)$ & $121(80.7)$ & 0.373 \\
\hline & $\geq 130 / 80$ & $43(20.9)$ & $14(25)$ & $29(19.3)$ & \\
\hline \multirow{2}{*}{$\begin{array}{l}\text { Plasma glucose } \\
(\mathrm{mmol} / \mathrm{L})\end{array}$} & $<5.6$ & $182(74)$ & $54(69.2)$ & $128(76.2)$ & 0.247 \\
\hline & $\geq 5.6$ & $64(26)$ & $24(30.8)$ & $40(23.8)$ & \\
\hline \multirow{2}{*}{$\begin{array}{l}\text { Triglycerides } \\
\text { (mmol/L) }\end{array}$} & $<1.7$ & $74(66.7)$ & $19(63.3)$ & $55(67.9)$ & 0.650 \\
\hline & $\geq 1.7$ & $37(33.3)$ & $11(36.7)$ & $26(32.1)$ & \\
\hline \multirow[t]{2}{*}{$\begin{array}{l}\text { Low HDL } \\
\text { (mmol/L) }\end{array}$} & $\begin{array}{l}\text { Male }<1.03 \\
\text { Female }<1.29\end{array}$ & $55(49.1)$ & $9(29)$ & $46(56.8)$ & $<0.01$ \\
\hline & $\begin{array}{l}\text { Male } \geq 1.03 \\
\text { Female }>1.29\end{array}$ & $57(50.9)$ & $22(71)$ & $35(43.2)$ & \\
\hline
\end{tabular}

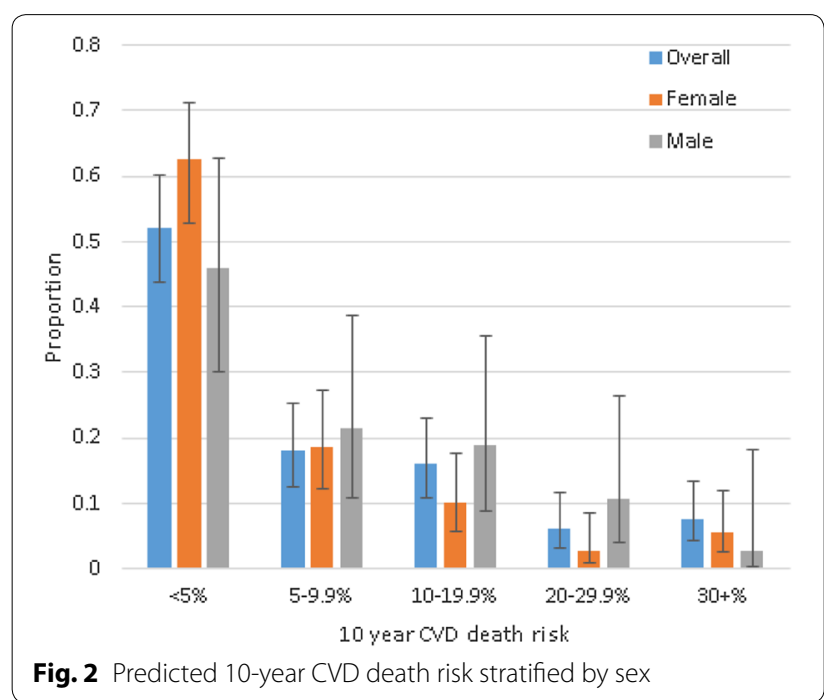

10-year cardiovascular mortality risk category, with 5 (33.33\%), $\mathrm{p}=0.002$ of patients at very high risk had MetS, (Additional file 1: Table S4).

\section{Duration of HIV infection, antiretroviral therapy and cardiovascular mortality risk}

Table 3 displays the estimation of the five categories of non-laboratory-based CVD mortality risk scores compared by age, duration of years of HIV infection, and ART use. We observed an increase in the mean age of our sample from very low-risk ( $37.52 \pm 4.50$ years), moderaterisk ( $48.05 \pm 5.64$ years), to the very high-risk score band (57.82 \pm 6.27 years). The median duration of HIV-infection confirmation among patients who were at a very low CVD mortality risk was 6.64 (3.63-9.86) years, while those at moderate-risk was $6.91(5.11-8.02)$ years and the very high-risk was 7.20 (4.49-11.05) years. Nonetheless, a higher proportion of patients who had been on ART for longer than $7.96 \pm 4.38$ years were in the high-risk score band, compared to the very low-risk $6.52 \pm 3.47$ years' band for CVD mortality. This study showed that duration of HIV infection and ART didn't correlate with the predicted CVD mortality risk categorized thresholds.

However, analysing the predicted 10-year CVD mortality risk as a continuous risk score and adjusting for patients' age, increasing duration of ART $(p=0.007)$ and HIV infection $(p=0.002)$ were significantly associated with increased patient's susceptibility to the risk of CVD mortality. (Additional file 1: Table S1).

\section{The proportion of other related factors with CVD mortality} risk

A bivariate analysis (Table 4) of our study sample could not suggest if race was associated with high or very high risk of CVD mortality among our population, as the proportion of Black Africans to other races in our study is not comparable. Patients who had changed from the first-line and were presently on second-line ART regimen [8/70 (11.43\%)], were more likely to be classified as very high risk than those on first-line treatment [3/73 (4.11\%)], but this was not statistically significant $(\mathrm{p}=0.211)$. Among those with previous tuberculosis infection, there appeared to be a lower likelihood of being at a very high risk of CVD compared to those without previous tuberculosis infection $[(3 / 70(4.29 \%)$ versus $8 / 72(11.11 \%)$, $\mathrm{p}=0.063]$. 
Table 3 Relationship between age, duration of HIV infection and antiretroviral therapy (in years) and cardiovascular mortality risk score classification

\begin{tabular}{|c|c|c|c|c|c|c|}
\hline \multirow[t]{2}{*}{ Variables (years) } & \multicolumn{5}{|l|}{ Risk score } & \multirow[b]{2}{*}{$P$-value ${ }^{i}$} \\
\hline & $<5.00 \%$ & $5.00-9.9 \%$ & $10.00-19.9 \%$ & $20.00-29.9 \%$ & $>30.00 \%$ & \\
\hline \multicolumn{7}{|l|}{ Age } \\
\hline N & 75 & 26 & 23 & 9 & 11 & \\
\hline Mean (SD) & $37.52(4.50)$ & $44.47(5.52)$ & $48.05(5.64)$ & $51.67(4.36)$ & $57.82(6.27)$ & Overall: $<0.001$ \\
\hline \multicolumn{7}{|c|}{ Duration of HIV infection } \\
\hline $\mathrm{N}$ & 41 & 16 & 12 & 7 & 5 & \\
\hline Median (P25-P75) & $6.64(3.63-9.86)$ & $8.11(4.46-11.07)$ & $6.91(5.11-8.02)$ & $7.41(2.20-12.10)$ & $11.51(7.11-11.69)$ & 0.684 \\
\hline \multicolumn{7}{|c|}{ Duration since ART initiation } \\
\hline $\mathrm{N}$ & 75 & 26 & 23 & 9 & 11 & \\
\hline Median (P25-P75) & $6.37(4.44-9.06)$ & $8.26(4.64-11.01)$ & $6.19(4.78-7.31)$ & $7.39(7.11-11.85)$ & $8.09(6.83-10.55)$ & 0.119 \\
\hline
\end{tabular}

One-way analysis of variance ANOVA with Bonferroni correction for multiple testing

Table 4 Bivariate analysis of factors associated with CVD mortality risk

\begin{tabular}{|c|c|c|c|c|c|c|c|}
\hline Variables & Total $(\mathrm{N}=144)$ & $<5.00 \%$ & $5.00-9.90 \%$ & $10.00-19.90 \%$ & $20.00-29.90 \%$ & $>30.00 \%$ & $P$ value \\
\hline Black Africans & 133 & $71(53.38)$ & $24(18.05)$ & $23(17.29)$ & $9(6.77)$ & $6(4.51)$ & $<0.001^{\mathrm{T}}$ \\
\hline Other races ${ }^{a}$ & 11 & $4.0(36.36)$ & $2(18.18)$ & - & - & $5(45.45)$ & \\
\hline 1st line regimen & 73 & $37(50.68)$ & $13(17.81)$ & $16(21.92)$ & $4(5.48)$ & $3(4.11)$ & $0.211^{*}$ \\
\hline 2nd line regimen & 70 & $37(52.86)$ & $13(18.57)$ & $7(10)$ & $5(7.14)$ & $8(11.43)$ & \\
\hline Previous tuberculosis & 70 & $44(62.86)$ & $8(11.43)$ & $11(15.71)$ & $4(5.71)$ & $3(4.29)$ & $0.063^{\mathrm{T}}$ \\
\hline No tuberculosis & 72 & $30(41.67)$ & $18(25.00)$ & $11(15.28)$ & $5(6.94)$ & $8(11.11)$ & \\
\hline
\end{tabular}

${ }^{\mp}$ Fisher's exact test; * Pearson Chi square $\left(x^{2}\right)$ test, ${ }^{a}$ Coloured and White

Analysing 10-year cardiovascular mortality risk as a linear variable using a continuous regression formulation (Bivariate and multivariable adjusted), age $(\mathrm{p}<0.001)$ remained independently associated with 10 year predicted CVD mortality risk. The analyses also suggest an association between African ethnicity $(\mathrm{p}<0.001)$, having previous TB infection $(\mathrm{p}=0.014)$ and being female $(\mathrm{p}<0.001)$ and increased CVD mortality risk.

There was no difference in baseline CD4 when comparing individuals with MetS to those without (median baseline CD4 of 452.5 [IQR: 332-667] versus 390 [IQR: $210-589$ ], $\mathrm{p}$-value $=0.285$ ). Furthermore, median baseline CD4 ranged from 363 (IQR: 227-525) among those classified with $<5 \% 10$-year cardiovascular mortality risk to 389.5 (IQR: 194-508) among those with 30+\% 10-year cardiovascular mortality risk ( $\mathrm{p}$-value $=0.484)$.

\section{Discussion}

HIV-infected and treated patients are susceptible to increased CVD risk factors, as well as cardiovascular morbidity and mortality outcomes. Although this susceptibility is associated with traditional risk factors, HIV infection, antiretroviral regimen and dynamics that emanate from the infection may also contribute to increased cardiovascular risk [35-37]. This present study reports the proportion of metabolic syndrome, metabolic risk factors and the associations thereof with the duration of HIV infection and ART. We also predicted the 10-year CVD mortality risk in HIV-infected patients treated for a mean duration of 6.18 years.

The study participants are aged 30 years and above, with the mean age of $42.90 \pm 8.20$. Most of the patients (45\%) have had tuberculosis in the past, which emphasizes the epidemic of HIV/TB co-infection in South Africa [38]. We realised a significantly high prevalence of overweight and obesity among our patients. These were more prevalent among the female participants, and confirms the epidemic of obesity in our setting [39]. Most of our study samples had normal blood pressure (79.1\%), though this was a baseline record. There is a probability of increase blood pressure over time among the population that was not monitored, understanding that South Africa has high burden of high blood pressure [40]. Recent study in South Africa among HIV infected cohort showed a high prevalence of hypertension at baseline and about $15 \%$ increased prevalence at follow -up after ART initiation [41]. In Denmark, a low prevalence of hypertension was reported in their population [42]. However, 
this outcomes depends on ART adherence, type of ART use and the study population [41]. Our study found an increased prevalence of MetS (17.5\%), especially in African women and supports the known increased high age-standardized CVD mortality rate in South Africa, driven by high blood pressure and obesity [43]. Agestandardized CVD mortality is increasing in sub-Saharan Africa countries, though varies by countries and mostly driven by growing age and population's health transition from communicable to non-communicable diseases [44-46]. Obesity and overweight, associated with the increasing presence of lipid disorder such as low HDL cholesterol and raised triglycerides, is prevalent in HIVinfected patients [47, 48]. This factors are associated with the development of metabolic disorder and CVD outcomes and this was indicated in our results. Additionally, related studies conducted in some Northern American and Europe reported that people living with HIV with increased age (45-60 years) were more inclined to die from CVD compared to the general population [26, 49], as our study indicates.

We showed that most of the study samples (52\%) were at a very low risk of CVD mortality, especially women. In Uganda, a large HIV positive cohort population study, showed that men were at high 10-year risk of acute CVD and ART treated populations were more at risk of longer term CVD, as suggested in our study [25]. Of our study patients, $8 \%$ were shown to be at greater than a $30 \% 10$-year risk of CVD mortality, similar to what was reported among a general population $(5.7 \%$ and above) with a comparable age range in Germany and India $[50,51]$. We have shown that there is a linear association between older age, patients who have been on ART for longer, and are in the high-risk score band (7.96 \pm 4.38 years) compared to very low risk (6.51 \pm 3.47 years) for CVD mortality. Predicted CVD mortality risk was not associated with the duration of treatment or HIV infection using the categorized threshold scores but was independently associated with increased age. Moreover, in a multivariate analysis and adjusting for age, duration of HIV infection and ART were significantly associated with 10 years predicted CVD mortality risk. This result emphasizes the additional effect of HIV related and individual components of MetS on the susceptibility to CVD mortality risk, at the absence of increased age. HIV infection, immune activation and inflammation are related to cardiovascular risk among the population, characterized by the complex interaction of systematic factors at all stages of HIV-infection progression [13, 16]. Likewise, both untreated HIV-infected and treated persons are adversely susceptible to CVD outcomes [19]. Nonetheless, studies have suggested CVD development to be more greatly associated with the duration and type of ART regimen (specific classes) than HIV-infection itself [52-55]. A recent study strengthens this evidence, reporting a high prevalence of metabolic risk factors among infected patients who have been on a protease inhibitor regimen, with $35 \%$ cardiovascular mortality at a 30 -day endpoint $[56,57]$. HIV-infected patients have shown a substantial development of CVD and its outcome progression within three years of ART initiation [58]. Islam et al. [59] showed a yearly increasing CVD risk among treated HIV-infected patients, establishing that the duration of ART exposure is strongly associated with CVD outcome. Višković et al. [13] analyzed the association between the presence of CVD biomarkers and related HIV-infected patient characteristics. The results of their study showed a positive correlation between the duration of HIV infection and ART and the presence of CVD markers, with a median of 8 and 6 years respectively [13]. Though in a Danish population, ageing, duration of ART initiation and HIV infection were not related with the risk of CVD [60]. This present study indicates a linear probability of a 10-year CVD mortality risk among its patients and the relationship between duration of infection or treatment [61].

Several studies have suggested CVD as an increasing cause of mortality in HIV-infected patients [26, 49]. A report shows the existence of a mutual interaction between traditional risk factors and HIV related factors namely HIV infection and long-term use of ART [15]. The traditional factors include high BMI, low HDL, which has shown to be prevalent among this study participants. American Heart Association recently reported that high BMI has shown to be independently associated with significant higher risk of death attributable to CVD [62]. In South Africa, participants with mean age 46 years and mostly African men, were within moderate to high CVD risk, in the presence of increased metabolic factors such as high blood pressure, high blood glucose [63]. Our study relates with literature that CVD death among HIV infected population has increased over the same period AIDS mortality decreased, even after matching and controlling for CVD known risk factors [64]. A huge reduction of CVD mortality is feasible by improving the distribution of risk factors in a population, which is applicable in our participants [65]. Treated HIV patients are clearly at a comparable CVD risk as general population, with the strong influence of aging HIV population. HIV infected population study in Brazil showed that HIV specific risk factors were strongly associated with CVD mortality risk than the traditional risk factors as age [66]. This variation emphasizes the complex interplay of different sets of risk factors for CVD mortality by populations [67]. This underlines the emerging need for an 
enhanced CVD risk-prediction model for HIV-infected populations, as a CVD mortality prediction tool has been reported to underestimate cardiovascular risk in HIV patients [26, 68, 69]. Studies have argued that the relationship between risks of CVD in HIV populations remains obscure and inconclusive, as the clinical significance of an absolute risk of CVD risk remains low in the HIV-infected population, specifically with certain types of ART [70,71].

Our study indicated most of the population were at low risk of CVD mortality. Noteworthy is the modest population size used for the estimation, which might not give the true reflection of the general population. Our study suggests that screening of CVD risk factors (as noted by the large number of missing information during the patient record review) occurs less frequently in healthcare practice than is recommended [72]. This resulted in few patients with complete variables for more precise estimation of CVD mortality risk compared to the target study sample size initially Our results are of interest and importance to public health, while taking our limitations into account. We relied on hospital -based patient medical chart reported diagnoses, though these might not be complete and entirely give accurate representation of our population, resulting in underestimation. Most of our subjects were females and of the African race, our results may not be generalizable to other populations. We have used cross-sectional data (chart audit) to predict the relationship between the duration of HIV infection and ART on cardiovascular mortality risk, hence causation cannot be ascertained. We were unable to include an HIVuninfected control population from the same region to compare the 10-year CVD risk. Moreover, studies among the South African general population have reported a high prevalence of CVD risk factors, ranging between 21.8 and $42.6 \%$ specifically among females [73-75]. This study also acknowledges another limitation in that we used the South African national smoking proportion to estimate the prevalence of smoking among our present population. However, this variable does not contribute much weight to our analysis [76]. Our study was not able to incorporate cholesterol concentrations as one of the variables of the CVD mortality risk estimation; however, the use of BMI is equally reliable for the prediction [32]. Nevertheless, we found a high proportion of metabolic risk factors with the possibility of cardiovascular mortality risk in a population of treated and stable HIVinfected patients. Our study recommends the scaling up of the routine monitoring of CVD risk factors during the management of HIV infection and treatment. This is supported by studies that have shown the increased susceptibility of the general population to CVD, including people living with HIV $[16,77]$.

\section{Conclusions}

In summary, in a South African population infected with HIV for a mean duration of 6 years, we found relationship between duration of infection and duration of ART use with a 10 -year predicted CVD mortality risk. However, predicted CVD mortality risk was strongly associated with age, as would also be expected in an uninfected population. Where 1 in 2 participants had increased adiposity, only $7 \%$ had hypertension. There was an implication of increased age, HIV infection and ART to the population's predisposition to a predicted 10 -year cardiovascular mortality risk. This implies that treated HIV patients should be as equally considered for CVD risk management as would be uninfected patients. However, modifiable risk factors may also have increased their susceptibility, so further studies are needed to clarify the risk differences between the contribution of traditional risk factors and HIV-related factors. This will assist with planning early prevention and management of metabolic risk factors and cardiovascular disorder outcomes in HIV-infected populations.

\section{Supplementary information}

Supplementary information accompanies this paper at https://doi. org/10.1186/s13098-019-0502-2.

Additional file 1: Table S1: Bivariate linear analysis of CVD Mortality risk. Table S2. Multivariable linear analysis of CVD Mortality risk. Table S3. Prevalence of Metabolic syndrome by Age distribution. Table S4. Prevalence of Metabolic syndrome by CVD mortality risk categories.

\section{Abbreviations}

HIV: human immunodeficiency virus; CVD: cardiovascular disease; MetS: metabolic syndrome; HDL: high density lipoprotein; SSAs: sub-Sahara African countries; HICs: high-income countries; LMICs: low-and-middle-income countries.

\section{Acknowledgements}

Not applicable.

\section{Authors' contributions}

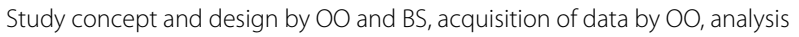
by $\mathrm{BS}$ and interpretation by $\mathrm{OO}, \mathrm{BS}$ and $\mathrm{AES}$, drafting of the manuscript by $\mathrm{OO}$, critical revision of the manuscript by OO, BS, AES and NM and study supervision by BS. All authors read and approved the final manuscript.

\section{Funding}

The work was supported through the Sub-Saharan African Network for TB/HIV Research Excellence (SANTHE), a DELTAS Africa Initiative [Grant \# DEL-15-006]. The DELTAS Africa Initiative is an independent funding scheme of the African Academy of Sciences (AAS) with its Alliance for Accelerating Excellence in Science in Africa (AESA) and is supported by the New Partnership for Africa's Development Planning and Coordinating Agency (NEPAD Agency) with funding from the Wellcome Trust [Grant \# 107752/Z/15/Z] and the UK government. The views expressed in this publication are those of the author (s) and not necessarily those of the AAS, NEPAD Agency, Wellcome Trust or the UK government.

\section{Availability of data and materials}

The dataset used and/or analyzed during the current study are available from the corresponding author on reasonable request. 


\section{Ethics approval and consent of participants}

Ethical approval for this study was obtained from the Biomedical Research Ethics Committee (BREC), reference number (BE437/16), at the University of KwaZulu-Natal and gatekeeper permission was obtained from Addington Hospital, reference number (9/2/3/R), to access the case files.

\section{Consent of publication}

Not applicable.

\section{Competing interests}

The authors declare that they have no competing interests.

\section{Author details}

${ }^{1}$ Public Health Medicine, School of Nursing and Public Health, University of KwaZulu-Natal, Durban 4001, South Africa. ${ }^{2}$ Department of Health Metrics Sciences, School of Medicine, University of Washington, Seattle, USA. ${ }^{3}$ Department of Internal Medicine, Nelson R. Mandela School of Medicine, University of KwaZulu-Natal, Durban, South Africa. ${ }^{4}$ Faculty of Infectious and Tropical Medicine, London School of Hygiene and Tropical Medicine, London, UK. ${ }^{5}$ Hypertension in Africa Research Team, North-West University, Potchefstroom, South Africa. ${ }^{6}$ Medical Research Council Unit for Hypertension and Cardiovascular Disease, North-West University, Potchefstroom, South Africa.

\section{Received: 8 August 2019 Accepted: 6 December 2019}

\section{Published online: 16 December 2019}

\section{References}

1. Volberding PA, Deeks SG. Antiretroviral therapy and management of HIV infection. Lancet. 2010;376(9734):49-62.

2. Levy M, Greenberg A, Hart R, Powers Happ L, Hadigan C, Castel A, Committee DCE, Benator D, Kumar P, Goldstein D. High burden of metabolic comorbidities in a citywide cohort of HIV outpatients: evolving health care needs of people aging with HIV in Washington, DC. HIV Med. 2017;18(10):724-35.

3. Palmeira dos Santos TM, da Silva BD, Franco MT, dos Santos RV, De Mendonca J, Dos Santos Júnior JA, Novais BG, Da Costa D. Lipodystrophy and the relationship with cardiovascular risk factors and metabolic syndrome in HIV-infected patients. Nutricion Clinica y Dietetica Hospitalaria. 2017;37(2):12-20

4. Malik S, Wong ND, Franklin SS, Kamath TV, Gilbert J, Pio JR, Williams GR. Impact of the metabolic syndrome on mortality from coronary heart disease, cardiovascular disease, and all causes in United States adults. Circulation. 2004;110(10):1245-50.

5. Palaniappan L, Carnethon MR, Wang Y, Hanley AJ, Fortmann SP, Haffner SM, Wagenknecht L. Predictors of the incident metabolic syndrome in adults: the insulin resistance atherosclerosis study. Diabetes Care. 2004;27(3):788-93.

6. Wilson PW, Kannel WB, Silbershatz H, D'Agostino RB. Clustering of metabolic factors and coronary heart disease. Arch Intern Med. 1999;159(10):1104-9.

7. Abdul-Ghani M, DeFronzo RA, Del Prato S, Chilton R, Singh R, Ryder REJ. Cardiovascular disease and type 2 diabetes: has the dawn of a new era arrived? Diabetes Care. 2017:40(7):813-20.

8. Grundy SM. Metabolic syndrome: a multiplex cardiovascular risk factor. J Clin Endocrinol Metab. 2007;92(2):399-404

9. Cerrato E, D'Ascenzo F, Biondi-Zoccai G, Calcagno A, Frea S, Grosso Marra W, Castagno D, Omedè P, Quadri G, Sciuto F, et al. Cardiac dysfunction in pauci symptomatic human immunodeficiency virus patients: a meta-analysis in the highly active antiretroviral therapy era. Eur Heart J. 2013;34(19):1432-6.

10. de Gaetano Donati K, Cauda R, lacoviello L. HIV infection, antiretroviral therapy and cardiovascular risk. Mediterr J Hematol Infect Dis. 2010;2(3):e2010034.

11. Solomon D, Sabin CA, Mallon PWG, Winston A, Tariq S. Cardiovascular disease in women living with HIV: a narrative review. Maturitas. 2018;108:58-70.

12. Gutierrez J, Albuquerque ALA, Falzon L. HIV infection as vascular risk: a systematic review of the literature and meta-analysis. PLOS ONE. 2017;12(5):e0176686
13. Višković K, Lepej SŽ, Gorenec A, Grgić I, Lukas D, Zekan Š, Dragobratović A, Trupković M, Begovac J. Cardiovascular markers of inflammation and serum lipid levels in HIV-infected patients with undetectable viremia. Sci Rep. 2018;8(1):6113.

14. Cerrato E, Calcagno A, D’Ascenzo F, Biondi-Zoccai G, Mancone M, Grosso Marra W, Demarie D, Omedè P, Abbate A, Bonora S, et al. Cardiovascular disease in HIV patients: from bench to bedside and backwards. Open Heart. 2015;2(1):e000174.

15. Freiberg MS, So-Armah K. HIV and cardiovascular disease: we need a mechanism, and we need a plan. J Am Heart Assoc. 2016;5(3):e003411.

16. Triant VA. Cardiovascular disease and HIV infection. Curr HIV/AIDS Rep. 2013;10(3):199-206.

17. Mesquita EC, Coelho LE, Amancio RT, Veloso V, Grinsztejn B, Luz P, Bozza FA. Severe infection increases cardiovascular risk among HIV-infected individuals. BMC Infect Dis. 2019;19(1):319.

18. Laurence J, Elhadad S, Ahamed J. HIV-associated cardiovascular disease: importance of platelet activation and cardiac fibrosis in the setting of specific antiretroviral therapies. Open Heart. 2018;5(2):e000823.

19. Palella FJ Jr, Phair JP. Cardiovascular disease in HIV infection. Curr Opin HIV AIDS. 2011:6(4):266-71.

20. Triant VA, Lee H, Hadigan C, Grinspoon SK. Increased acute myocardial infarction rates and cardiovascular risk factors among patients with human immunodeficiency virus disease. J Clin Endocrinol Metab. 2007:92(7):2506-12.

21. Isomaa B, Almgren $P$, Tuomi T, Forsén B, Lahti K, Nissén M, Taskinen M-R, Groop L. Cardiovascular morbidity and mortality associated with the metabolic syndrome. Diabetes Care. 2001;24(4):683-9.

22. Lakka H, Laaksonen DE, Lakka TA, et al. The metabolic syndrome and total and cardiovascular disease mortality in middle-aged men. JAMA. 2002;288(21):2709-16.

23. Dimala CA, Blencowe $\mathrm{H}$, Choukem SP. The association between antiretroviral therapy and selected cardiovascular disease risk factors in sub-Saharan Africa: a systematic review and meta-analysis. PLOS ONE. 2018;13(7):e0201404.

24. Patel $P$, Rose CE, Collins PY, Nuche-Berenguer B, Sahasrabuddhe W, Peprah E, Vorkoper S, Pastakia SD, Rausch D, Levitt NS, et al. Noncommunicable diseases among HIV-infected persons in low-income and middle-income countries: a systematic review and meta-analysis. AIDS. 2018;32:S5-20

25. Mateen FJ, Kanters S, Kalyesubula R, Mukasa B, Kawuma E, Kengne AP, Mills EJ. Hypertension prevalence and Framingham risk score stratification in a large HIV-positive cohort in Uganda. J Hypertens. 2013;31(7):1372-8.

26. Feinstein MJ, Bahiru E, Achenbach C, Longenecker CT, Hsue P, So-Armah K, Freiberg MS, Lloyd-Jones DM. Patterns of cardiovascular mortality for HIV-infected adults in the United States: 1999 to 2013. Am J Cardiol. 2016;117(2):214-20

27. D'Agostino RB, Vasan RS, Pencina MJ, Wolf PA, Cobain M, Massaro JM, Kannel WB. General cardiovascular risk profile for use in primary care: the Framingham Heart Study. Circulation. 2008;117(6):743-53.

28. Meintjes G, Moorhouse MA, Carmona S, Davies N, Dlamini S, Van Vuuren C, Manzini T, Mathe M, Moosa Y, Nash J. Adult antiretroviral therapy guidelines 2017. South Afr J HIV Med. 2017;18(1):1-24.

29. Peer N, Lombard C, Steyn K, Gaziano T, Levitt N. Comparability of total cardiovascular disease risk estimates using laboratory and non-laboratory based assessments in urban-dwelling South Africans: the CRIBSA study. S Afr Med J. 2014;104(10):691-6.

30. Gaziano TA, Young CR, Fitzmaurice G, Atwood S, Gaziano JM. Laboratory-based versus non-laboratory-based method for assessment of cardiovascular disease risk: the NHANES I Follow-up Study cohort. Lancet. 2008;371(9616):923-31.

31. Organisation WH. Prevention of cardiovascular disease: guidelines for assessment and management of total cardiovascular risk. Geneva: WHO; 2007.

32. Gaziano TA, Pandya A, Steyn K, Levitt N, Mollentze W, Joubert G, Walsh CM, Motala AA, Kruger A, Schutte AE, et al. Comparative assessment of absolute cardiovascular disease risk characterization from nonlaboratory-based risk assessment in South African populations. BMC Med. 2013;11:170.

33. Zimmet P, Alberti KG, Serrano Ríos M. A new international diabetes federation worldwide definition of the metabolic syndrome: the rationale 
and the results. Revista Española de Cardiología (English Edition). 2005;58(12):1371-5.

34. Stata S. Release 13. Statistical software. College Station: StataCorp LP; 2013.

35. Baker JV, Sharma S, Achhra AC, Bernardino Jl, Bogner JR, Duprez D, Emery S, Gazzard B, Gordin J, Grandits G. Changes in cardiovascular disease risk factors with immediate versus deferred antiretroviral therapy initiation among hiv-positive participants in the START (Strategic Timing of Antiretroviral Treatment) Trial. J Am Heart Assoc. 2017;6(5):e004987.

36. Osegbe ID, Soriyan OO, Ogbenna AA, Okpara HC, Azinge EC. Risk factors and assessment for cardiovascular disease among HIV-positive patients attending a Nigerian tertiary hospital. Pan Afr Med J. 2016. https://doi. org/10.11604/pamj.2016.23.206.7041.

37. Nsagha DS, Assob JCN, Njunda AL, Tanue EA, Kibu OD, Ayima CW, Ngowe MN. Risk factors of cardiovascular diseases in HIV/AIDS patients on HAART. Open AIDS J. 2015;9:51-9.

38. Karim SSA, Churchyard GJ, Karim QA. Lawn SDJtL: HIV infection and tuberculosis in South Africa: an urgent need to escalate the public health response. 2009;374(9693):921-33.

39. Sartorius B, Veerman LJ, Manyema M, Chola L, Hofman K. Determinants of obesity and associated population attributability, South Africa: empirical evidence from a national panel survey, 2008-2012. PLoS ONE. 2015;10(6):e0130218.

40. Norman R, Gaziano T, Laubscher R, Steyn K, Bradshaw D, Collaboration SA. Estimating the burden of disease attributable to high blood pressure in South Africa in 2000. South Afr Med J. 2007;97(8):692-8.

41. Brennan AT, Jamieson L, Crowther NJ, Fox MP, George JA, Berry KM, Stokes A, Maskew M, Sanne I, Long L, Cassim N. Prevalence, incidence, predictors, treatment, and control of hypertension among HIV-positive adults on antiretroviral treatment in public sector treatment programs in South Africa. PloS one. 2018;13(10):e0204020.

42. Gelpi M, Afzal S, Lundgren J, Ronit A, Roen A, Mocroft A, Gerstoft J, Lebech AM, Lindegaard B, Kofoed KF, et al. Higher Risk of Abdominal Obesity, Elevated Low-Density Lipoprotein Cholesterol, and Hypertriglyceridemia, but not of Hypertension, in People Living With Human Immunodeficiency Virus (HIV): Results From the Copenhagen Comorbidity in HIV Infection Study. Clin Infect Dis. 2018;67(4):579-86.

43. Schutte AE. Urgency for South Africa to prioritise cardiovascular disease management. Lancet Glob Health. 2019;7(2):e177-8.

44. Mensah GA, Roth GA, Sampson UK, Moran AE, Feigin VL, Forouzanfar $\mathrm{MH}$, Naghavi M, Murray CJ. Mortality from cardiovascular diseases in subSaharan Africa, 1990-2013: a systematic analysis of data from the Global Burden of Disease Study 2013. Cardiovasc J Afr. 2015;26(2 Suppl 1):S6-10.

45. Ayinde H, Gillum RF. Cardiovascular disease mortality in Sub-Saharan Africa and the Caribbean. Ethn Dis. 2014;24(4):495-501.

46. Keates AK, Mocumbi AO, Ntsekhe M, Sliwa K, Stewart S. Cardiovascular disease in Africa: epidemiological profile and challenges. Nat Rev Cardiol. 2017;14(5):273.

47. Crum-Cianflone N, Tejidor R, Medina S, Barahona I, Ganesan A. Obesity among HIV patients: the latest epidemic. AIDS Patient Care STDs. 2008;22(12):925-30.

48. Guehi C, Badjé A, Gabillard D, Ouattara E, Koulé SO, Moh R, Ekouevi D, Ahibo H, N'Takpé JB, Menan GK, et al. High prevalence of being overweight and obese HIV-infected persons, before and after 24 months on early ART in the ANRS 12136 Temprano Trial. AIDS Res Ther. 2016;13:12.

49. Trickey A, May MT, Vehreschild J, Obel N, Gill MJ, Crane H, Boesecke C, Samji H, Grabar S, Cazanave C. Cause-specific mortality in HIV-positive patients who survived ten years after starting antiretroviral therapy. PLoS ONE. 2016;11(8):e0160460.

50. Diederichs C, Neuhauser H, Rücker V, Busch MA, Keil U, Fitzgerald AP, Heuschmann PU. Predicted 10-year risk of cardiovascular mortality in the 40 to 69 year old general population without cardiovascular diseases in Germany. PLoS ONE. 2018;13(1):e0190441.

51. Jeemon P, Prabhakaran D, Huffman MD, Ramakrishnan L, Goenka S, Thankappan KR, Mohan V, Joshi PP, Mohan BVM, Ahmed F, et al. Distribution of 10-year and lifetime predicted risk for cardiovascular disease in the Indian Sentinel Surveillance Study population (cross-sectional survey results). BMJ Open. 2011;1(1):e000068.

52. Strategies for Management of Antiretroviral Therapy (SMART) Study Group. CD4+ count-guided interruption of antiretroviral treatment. N Engl J Med. 2006;355(22):2283-96.
53. Hulten E, Mitchell J, Scally J, Gibbs B, Villines T. HIV positivity, protease inhibitor exposure, and subclinical atherosclerosis: a systematic review and meta-analysis of observational studies. Heart. 2009. https://doi. org/10.1136/hrt.2009.177774.

54. Friis-Moller N, Sabin CA, Weber R, d'Arminio Monforte A, El-Sadr WM, Reiss P, Thiebaut R, Morfeldt L, De Wit S, Pradier C, et al. Combination antiretroviral therapy and the risk of myocardial infarction. N Engl J Med. 2003;349(21):1993-2003.

55. Durand M, Sheehy O, Baril J-G, Lelorier J, Tremblay CL. Association between HIV infection, antiretroviral therapy, and risk of acute myocardial infarction: a cohort and nested case-control study using Québec's Public Health Insurance Database. JAIDS J Acquir Immune Defic Syndr. 2011;57(3):245-53.

56. Alvi RM, Neilan AM, Tariq N, Awadalla M, Afshar M, Banerji D, Rokicki A, Mulligan C, Triant VA, Zanni MV, et al. Protease inhibitors and cardiovascular outcomes in patients with HIV and heart failure. J Am Coll Cardiol. 2018;72(5):518-30.

57. Echecopar-Sabogal J, D'Angelo-Piaggio L, Chanamé-Baca DM, UgarteGil C. Association between the use of protease inhibitors in highly active antiretroviral therapy and incidence of diabetes mellitus and/or metabolic syndrome in HIV-infected patients: a systematic review and meta-analysis. Int J STD AIDS. 2017;29(5):443-52.

58. Wand H, Calmy A, Carey DL, Samaras K, Carr A, Law MG, Cooper DA, Emery S. Committee obotITIC: metabolic syndrome, cardiovascular disease and type 2 diabetes mellitus after initiation of antiretroviral therapy in HIV infection. AIDS. 2007;21(18):2445-53.

59. Islam FM, Wu J, Jansson J, Wilson DP. Relative risk of cardiovascular disease among people living with HIV: a systematic review and meta-analysis. HIV Med. 2012;13(8):453-68.

60. Rasmussen LD, May MT, Kronborg G, Larsen CS, Pedersen C, Gerstoft J, Obel N. Time trends for risk of severe age-related diseases in individuals with and without HIV infection in Denmark: a nationwide populationbased cohort study. Lancet HIV. 2015;2(7):e288-98.

61. Freiberg MS, So-Armah K. HIV and cardiovascular disease: we need a mechanism, and we need a plan. In.: Am Heart Assoc; 2016.

62. Benjamin EJ, Muntner P, Bittencourt MS. Heart disease and stroke statistics-2019 update: a report from the American Heart Association. Circulation. 2019;139(10):e56-528.

63. Burger A, Pretorius R, Fourie CMT, Schutte AE. The relationship between cardiovascular risk factors and knowledge of cardiovascular disease in African men in the North-West Province. Health SA Gesondheid. 2016;21:364-71.

64. Kaplan RC, Hanna DB, Kizer JR. Recent insights into cardiovascular disease (CVD) risk among HIV-infected adults. Current HIV/AIDS. 2016;13(1):44-52.

65. Ford ES, Capewell S. Proportion of the decline in cardiovascular mortality disease due to prevention versus treatment: public health versus clinical care. Annu Rev Public Health. 2011;32:5-22.

66. Diaz CM, Segura ER, Luz PM, Clark JL, Ribeiro SR, De Boni R, Eksterman L, Moreira R, Currier JS, Veloso VG, et al. Traditional and HIV-specific risk factors for cardiovascular morbidity and mortality among HIV-infected adults in Brazil: a retrospective cohort study. BMC Infect Dis. 2016;16:376.

67. Vishram JK. Prognostic interactions between cardiovascular risk factors. Dan Med J. 2014;61(7):B4892.

68. Bjørngaard JH, Vie GÅ, Krokstad S, Janszky I, Romundstad PR, Vatten LJ. Cardiovascular mortality — comparing risk factor associations within couples and in the total population - the HUNT Study. Int J Cardiol. 2017:232:127-33.

69. Feinstein MJ, Hsue PY, Benjamin LA, Bloomfield GS, Currier JS, Freiberg MS, Grinspoon SK, Levin J, Longenecker CT, Post WS. Characteristics, prevention, and management of cardiovascular disease in people living with HIV: a scientific statement from the American Heart Association. Circulation. 2019. https://doi.org/10.1161/CIR.0000000000000695.

70. Das S. Risk of cardiovascular disease in HIV-infected patients. J Antimicrob Chemother. 2010;65(3):386-9.

71. Currier JS, Lundgren JD, Carr A, Klein D, Sabin CA, Sax PE, Schouten JT, Smieja M. 2 WG: epidemiological evidence for cardiovascular disease in HIV-infected patients and relationship to highly active antiretroviral therapy. Circulation. 2008;1 18(2):e29-35.

72. Seedat $Y$, Rayner $B$, Veriava Y. South African hypertension practice guideline 2014. Cardiovasc J Afr. 2014;25(6):288. 
73. Kruger MJ, Nell TA. The prevalence of the metabolic syndrome in a farm worker community in the Boland district, South Africa. BMC Public Health. 2017;17(1):61.

74. Owolabi EO, Ter Goon D, Adeniyi OV, Adedokun AO, Seekoe E. Prevalence and correlates of metabolic syndrome among adults attending healthcare facilities in Eastern Cape, South Africa. Open Public Health J. 2017;10(1):148-59.

75. Erasmus RT, Soita DJ, Hassan MS, Blanco-Blanco E, Vergotine Z, Kengne AP, Matsha TE. High prevalence of diabetes mellitus and metabolic syndrome in a South African coloured population: baseline data of a study in Bellville, Cape Town. S Afr Med J. 2012;102(11):841-4.

76. Reddy P, Zuma K, Shisana O, Jonas K, Sewpaul R. Prevalence of tobacco use among adults in South Africa: results from the first South African
National Health and Nutrition examination survey. S Afr Med J. 2015;105(8):648-55.

77. Barnes RP, Lacson JCA, Bahrami H. HIV infection and risk of cardiovascular diseases beyond coronary artery disease. Curr Atheroscler Rep. 2017;19(5):20.

\section{Publisher's Note}

Springer Nature remains neutral with regard to jurisdictional claims in published maps and institutional affiliations.
Ready to submit your research? Choose BMC and benefit from:

- fast, convenient online submission

- thorough peer review by experienced researchers in your field

- rapid publication on acceptance

- support for research data, including large and complex data types

- gold Open Access which fosters wider collaboration and increased citations

- maximum visibility for your research: over $100 \mathrm{M}$ website views per year

At BMC, research is always in progress.

Learn more biomedcentral.com/submissions 